\title{
ADEQUAÇÃO DO VAPOR DE PROCESSO DE BAIXA PRESSÃO AO PADRÃO DE QUALIDADE REQUERIDO PARA A TURBINA A VAPOR NA TKCSA*
}

\section{Resumo}

Magda Moreira Pinto ${ }^{1}$

Durante a fabricação do aço as grandes siderúrgicas possuem usinas térmicas integradas aos seus processos industriais. Uma operação bastante comum na indústria siderúrgica é a geração de vapor, normalmente utilizado para a produção de trabalho mecânico em turbinas (vapor superaquecido) ou em processos de aquecimento, nos quais se emprega o vapor saturado. Estes vapores de processos também podem ser utilizados na geração de energia elétrica. Para isto, foi importante assegurar a qualidade da água e do vapor de baixa pressão (VBP) enviado para Termelétrica. Foi com este intuito que a TKCSA se preocupou em padronizar o (VBP) gerado na Caldeira Auxiliar da área de Utilidades e Caldeiras da Aciaria. O desafio era transformar o (VBP) na mesma qualidade do vapor produzido nas caldeiras recuperadoras de calor (HRSG). O procedimento adotado foi á modificação no tratamento químico, a instalação de uma monitoração química contínua e eficiente para assegurar os parâmetros químicos dentro da especificação técnica recomendada pelo EPRI - Electric Power Research Institute, Inc. Com este tratamento foi controlada as dosagens químicas, a operação da caldeira e a geração dos efluentes líquidos para o tratamento químico ambiental. Contudo foi possível tornar um mecanismo dinâmico e econômico para a empresa viabilizando a utilização do vapor na termelétrica.

Palavras-chave: Vapor de processo; Vapor de baixa pressão, Padrão de qualidade; Turbina á vapor.

\section{FITNESS OF STEAM PROCESS OF LOW PRESSURE TO QUALITY STANDARDS REQUIRED FOR STEAM TURBINE IN TKCSA}

\begin{abstract}
During the manufacture of steel major integrated steelmakers have their industrial processes thermal plants. A common operation in the steel industry is the generation of steam normally used to produce mechanical work turbine (superheated steam) or heating process in which saturated steam is used. These vapors processes can also be used to generate electricity. For this, it was important to ensure the quality of water and low pressure steam (VBP) Thermoelectric sent. It was with this intention that the CSA bothered to standardize (VBP) generated in the Auxiliary Boiler Area Utility Boiler and Steelmaking. The challenge was to turn (VBP) in the same quality of the steam produced in the boilers heat reclaimers (HRSG). The procedure adopted was the change in the chemical treatment, the installation of a continuous and efficient chemical monitoring to ensure the chemical parameters within the technical specification recommended by EPRI - Electric Power Research Institute, Inc. With this treatment was controlled chemical dosages, the operation the boiler and the generation of wastewater for environmental chemical treatment. However it was possible to make a dynamic economic engine for the company enabling the use of steam in the fuel.
\end{abstract}

Keywords: Process steam; Low pressure steam; Quality Standard; Steam turbine.

1 Bacharel em Química, MSc. Química, Química Sênior/Especialista, Unidade Técnica/Utilidades, ThyssenKrupp CSA Siderúrgica do Atlântico, Rio de Janeiro, RJ, Brasil.

* Contribuição técnica ao $35^{\circ}$ Seminário de Balanços Energéticos Globais e Utilidades e $29^{\circ}$ Encontro de Produtores e Consumidores de Gases Industriais, 13 a 15 de agosto de 2014, São Paulo, SP, Brasil. 


\section{INTRODUÇÃO}

No circuito água-vapor de uma usina térmica, água e vapor servem como:

- meio de transporte de energia;

- fluído de trabalho.

Na realização destas duas funções, água e vapor não devem afetar a operação da planta no sentido de causar a corrosão dos materiais estruturais.

As funções principais da química da água do circuito água-vapor podem ser divididas nos seguintes itens:

- minimizar a taxa de degradação (corrosão) dos materiais estruturais;

- evitar formas de corrosão seletiva;

- evitar depósitos de produtos de corrosão nas superfícies de transferência de calor;

- evitar a formação de meios agressivos.

Segundo Pinto [1], de acordo com estas funções existe uma dependência direta entre a seleção dos materiais estruturais e a química da água. $\mathrm{Na}$ operação da planta do ciclo água vapor certamente ocorre reações químicas e outras reações físicas. Sais dissolvidos e não dissolvidos na água causam corrosão e formação de depósitos nos componentes. Isto não afeta a função da planta, mas mais tarde pode ocasionar danos irreparáveis.

Estudos de turbinas nas plantas americanas [2] mostram as causas de mau funcionamento:

- $57 \%$ por formação de depósitos;

- $22 \%$ por corrosão;

- $21 \%$ por 'cracks'e atividade mecânica (agressividade química causada simultaneamente por formação de 'crack').

A usina térmica da TKCSA produz vapor de alta pressão (VAP) nas caldeiras recuperadoras de calor (HRSG) conforme as exigências do projeto da ALTOM [3] e atendimento as especificações técnicas do "EPRI". Mas também recebe vapor de alta pressão da Coqueria e vapor de baixa pressão da Aciaria e Caldeira Auxiliar da Utilidade. Estes vapores são direcionados para a turbina de alta e de baixa pressão. Para garantir os parâmetros do vapor dentro da especificação técnica, a qualidade da água desmineralizada deverá ser:

Tabela 1. Parâmetros de especificação da água desmineralizada [3]

\begin{tabular}{c|c|c}
\hline Parâmetros & Unidade & Especificação \\
\hline Condutividade Específica (a) & $\mu \mathrm{S} / \mathrm{cm}$ & $<0,1$ \\
\hline Condutividade Específica (b) & $\mu \mathrm{S} / \mathrm{cm}$ & $<0,5$ \\
\hline Sódio (Na) & $\mathrm{ppb}$ & $<10$ \\
\hline Sílica (SiO2) & $\mathrm{ppb}$ & $<20$ \\
\hline Ferro (Fe) & $\mathrm{ppb}$ & $<20$ \\
\hline Cobre (Cu) & $\mathrm{ppb}$ & $<3$ \\
\hline Carbono Orgânico Total (TOC) & $\mathrm{ppb}$ & $<300$
\end{tabular}

(a) Condutividade na saída do leito misto, (b) Condutividade no tanque de estocagem

Dependendo do tratamento da caldeira, os parâmetros de especificação para o tratamento proposto neste trabalho são:

* Contribuição técnica ao $35^{\circ}$ Seminário de Balanços Energéticos Globais e Utilidades e $29^{\circ}$ Encontro de Produtores e Consumidores de Gases Industriais, 13 a 15 de agosto de 2014, São Paulo, SP, Brasil. 


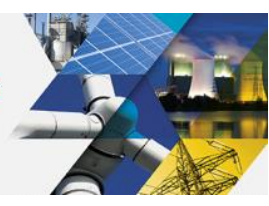

Tabela 2. Parâmetros de especificação da água da caldeira de baixa pressão [3]

\begin{tabular}{c|c|c}
\hline Parâmetros & Unidade & Especificação \\
\hline Condutividade Específica & $\mu \mathrm{S} / \mathrm{cm}$ & $<100$ \\
\hline $\mathrm{pH}$ a $25^{\circ} \mathrm{C}$ & - & $9,0-10,0$ \\
\hline Sílica $\left(\mathrm{SiO}_{2}\right)$ & $\mathrm{ppb}$ & $<200$ \\
\hline Ferro $(\mathrm{Fe})$ & $\mathrm{ppb}$ & $<200$ \\
\hline Cobre $(\mathrm{Cu})$ & $\mathrm{ppb}$ & $<10$ \\
\hline Oxigênio dissolvido $\left(\mathrm{O}_{2}\right)$ & $\mathrm{ppb}$ & $<100$ \\
\hline Amônia & $\mathrm{ppm}$ & $0,3-1,0$ \\
\hline Hidrazina & $\mathrm{ppm}$ & $0,5-1,0$ \\
\hline Dispersante (Molibdato) & $\mathrm{ppm}$ & $<0,165$ \\
\hline
\end{tabular}

Certamente, atendendo estes parâmetros químicos o vapor deverá ter:

Tabela 3. Parâmetros de especificação do vapor de baixa e alta pressão [3]

\begin{tabular}{c|c|c}
\hline Parâmetros & Unidade & Especificação \\
\hline Condutividade Catiônica (a) & $\mu \mathrm{S} / \mathrm{cm}$ & $<0,2$ \\
\hline Condutividade Específica (b) & $\mu \mathrm{S} / \mathrm{cm}$ & $<3-11$ \\
\hline $\mathrm{pH} \mathrm{a} 25^{\circ} \mathrm{C}$ & - & $9,0-9,6$ \\
\hline Sílica (SiO2) & $\mathrm{ppb}$ & $<20$ \\
\hline Ferro (Fe) & $\mathrm{ppb}$ & $<20$ \\
\hline Sódio (Na) & $\mathrm{ppb}$ & $<10$ \\
\hline
\end{tabular}

C̆om o intuito de minimizar problemas de corrosão e contaminação do vapor da usina térmica, a área da utilidade trabalhou na melhoria da qualidade dos vapores de baixa pressão oriundos da Caldeira da Aciaria e Caldeira da Utilidade.

Isto foi necessário para:

Assegurar a qualidade do VBP enviado para termelétrica da Caldeira da Aciaria e da

Caldeira Auxiliar da Utilidade para:

- Desaeração no tanque de água de alimentação principal;

- Operação do sistema de remoção de ar do condensador;

- Aquecimento do Gás combustível das TG's (BFG);

- Pré-aquecimento da água de alimentação para a Coqueria

A má qualidade do VBP enviado para termelétrica, ocasiona baixa eficiência de Vapor para:

- Turbina de Baixa Pressão;

- Remoção de ar do condensador;

- Pré-aquecimento da água de alimentação para a coqueria.

- Aquecimento do Gás combustível das TG's (BFG);

\section{MATERIAIS E MÉTODOS}

O sistema de dosagem desenvolvido pela Ashland para a Caldeira Auxiliar da Utilidade tem a função de dosar amina, sequestrante de oxigênio e dispersante de forma continua e precisa. Os equipamentos utilizados são bombas dosadoras digitais, bombas dosadoras de alta pressão e do controlador Onguard iController. Além disso, existem três sistemas de acondicionamento de amostra (água de alimentação, água da caldeira e vapor) com analisadores para medição de $\mathrm{pH}$,condutividade específica e condutividade catiônica (somente para vapor). Os sinais são enviados via 4-20mA para o controlador Onguard para garantir o monitoramento.

* Contribuição técnica ao $35^{\circ}$ Seminário de Balanços Energéticos Globais e Utilidades e $29^{\circ}$ Encontro de Produtores e Consumidores de Gases Industriais, 13 a 15 de agosto de 2014, São Paulo, SP, Brasil. 

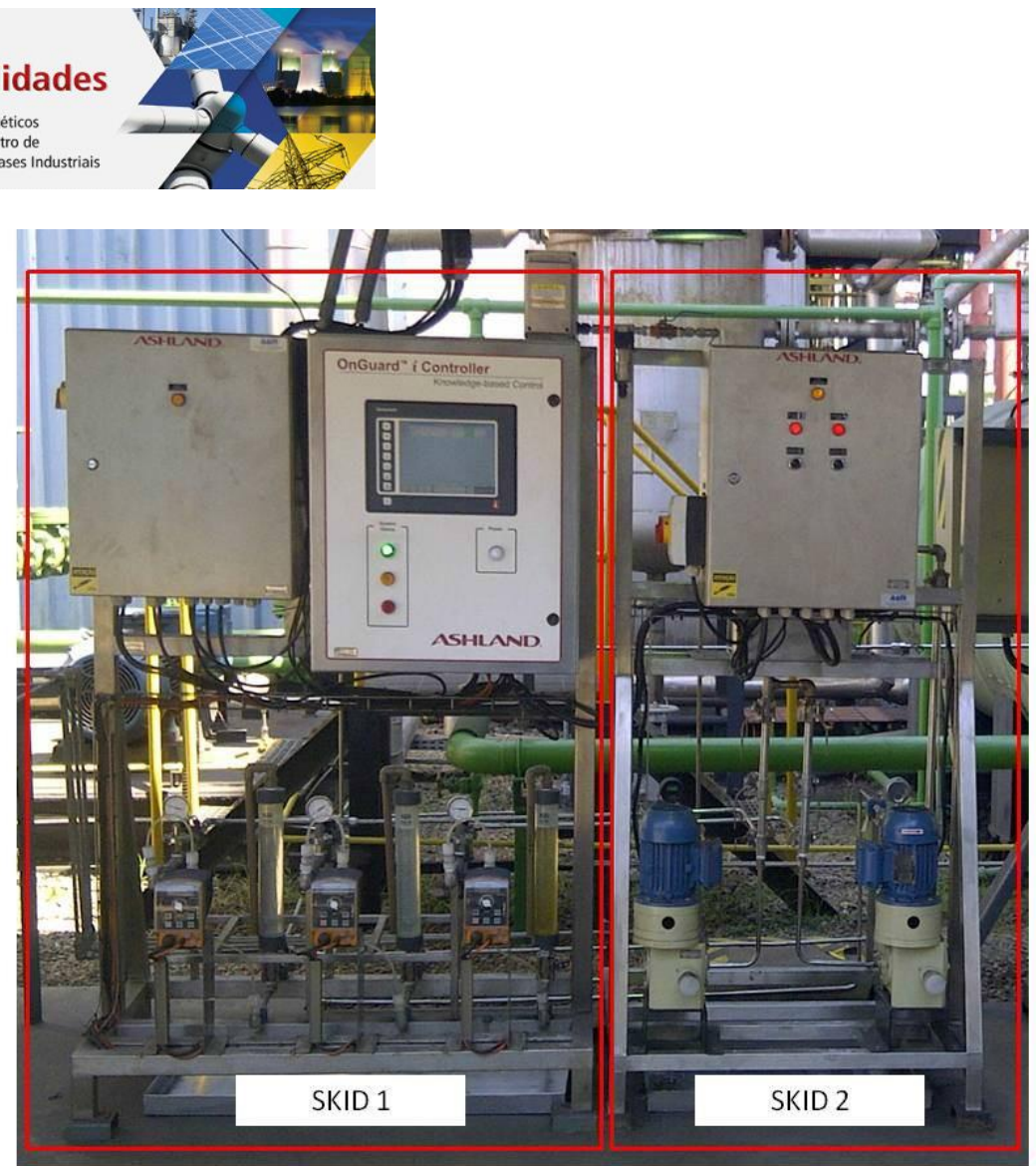

Figura 1. Apresentação dos skids 1 e 2.

04 - Tanques de armazenamento de produtos;

05 - Bombas pneumáticas para transferência de produtos químicos.

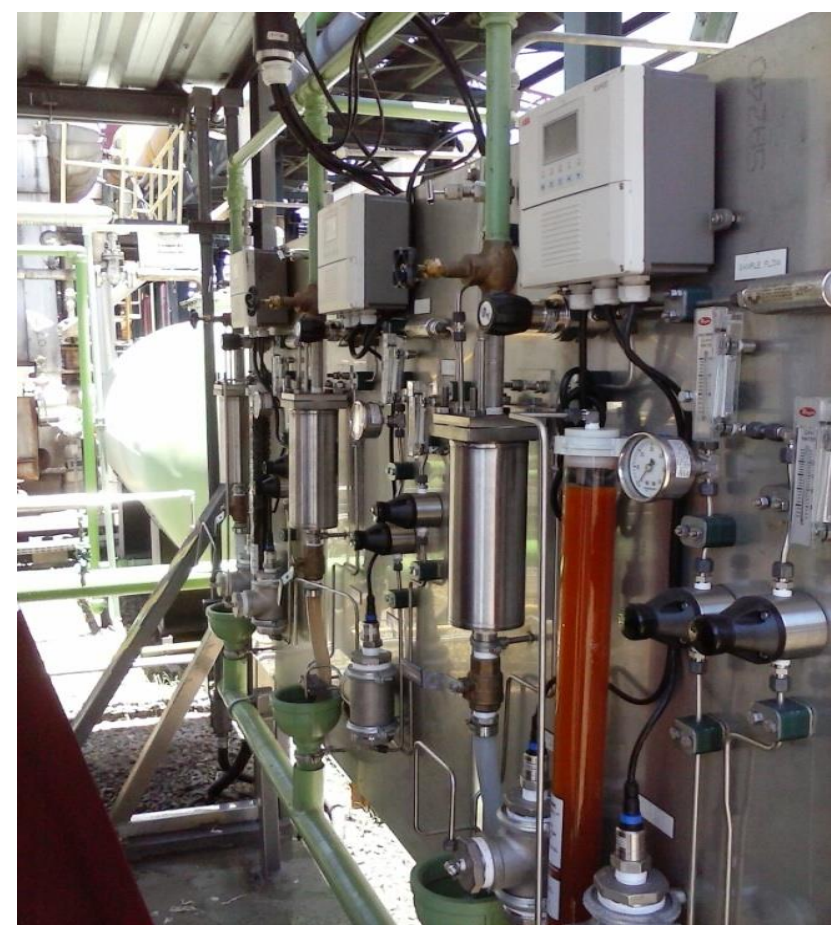

Figura 2. Painel de acondicionamento de amostra.

* Contribuição técnica ao $35^{\circ}$ Seminário de Balanços Energéticos Globais e Utilidades e $29^{\circ}$ Encontro de Produtores e Consumidores de Gases Industriais, 13 a 15 de agosto de 2014, São Paulo, SP, Brasil. 

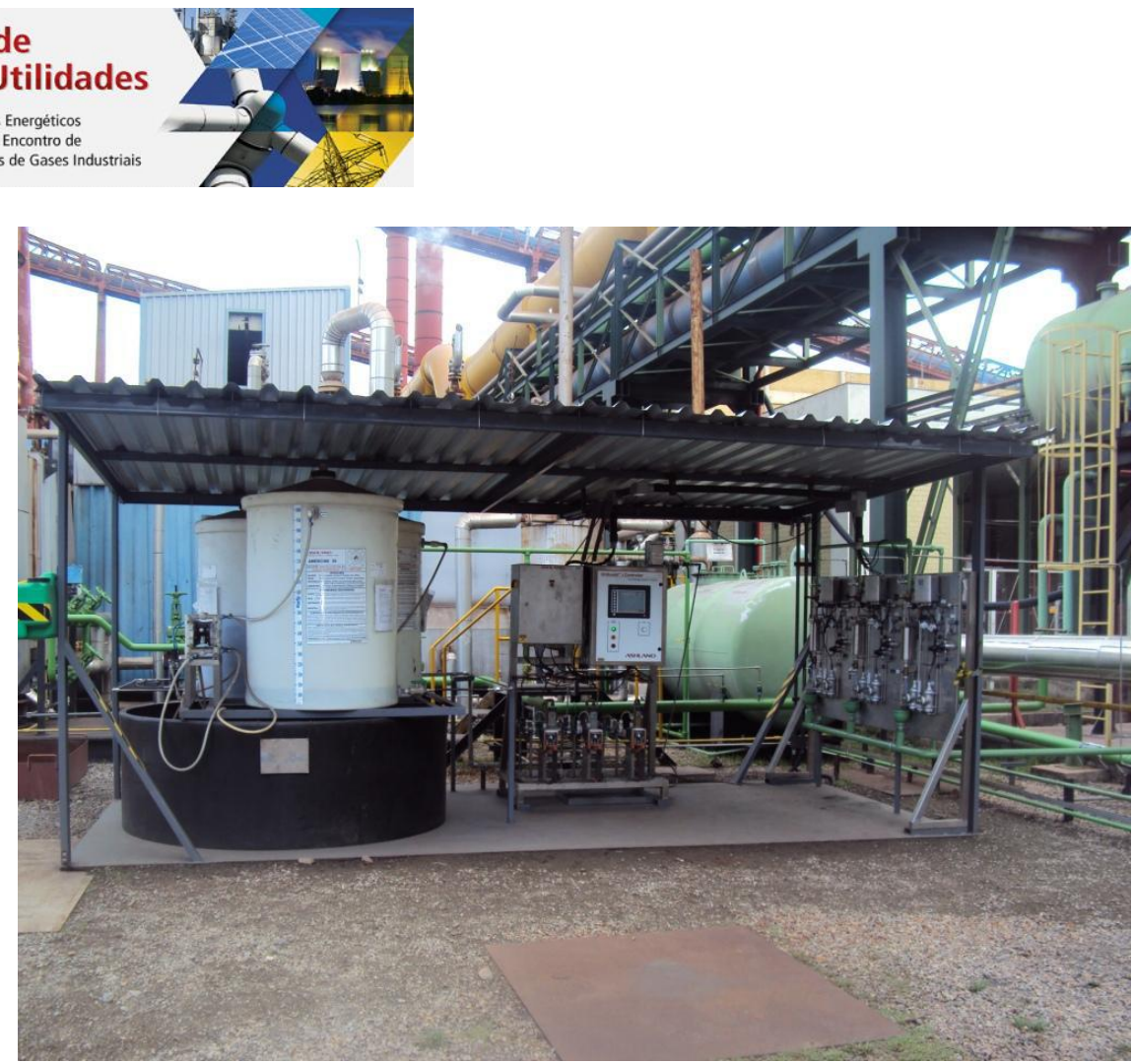

Figura 3. Visão geral do tratamento e monitoramento da caldeira.

\section{RESULTADOS E DISCUSSÃO}

O EPRI é reconhecido mundialmente e o mesmo assegura o que é praticado nas diversas usinas no mundo em forma de adoção das melhores práticas do mercado. A Tabela 4 apresenta a comparação dos diversos tipos de projetos utilizando a recomendação internacional.

Tabela 4. Parâmetros de especificação do vapor de baixa e alta pressão [4]

\begin{tabular}{c|c|c|c|c|c}
\hline Parâmetros & Unidade & $\begin{array}{c}\text { Especificação } \\
\text { Técnica }\end{array}$ & \multicolumn{3}{|c}{ Projetos } \\
\cline { 4 - 6 } & & & SIEMENS & ABB & ALSTOM \\
\hline $\begin{array}{c}\text { Condutividade } \\
\text { Catiônica }\end{array}$ & $\mu \mathrm{S} / \mathrm{cm}$ & $<0,2$ & $<0,2$ & $<0,2$ & $<0,2$ \\
\hline $\begin{array}{c}\text { Condutividade } \\
\text { Específica }\end{array}$ & $\mu \mathrm{S} / \mathrm{cm}$ & $<3-11$ & $<3-11$ & $<4-11$ & $<3-11$ \\
\hline pH a 25 ${ }^{\circ} \mathrm{C}$ & - & $9,0-9,8$ & $9,0-9,8$ & $9,0-9,6$ & $9,0-9,8$ \\
\hline Sílica (SiO2) & $\mathrm{ppb}$ & $<20$ & $<20$ & $<20$ & $<20$ \\
\hline Ferro (Fe) & $\mathrm{ppb}$ & $<20$ & $<20$ & $<20$ & $<20$ \\
\hline Sódio (Na) & $\mathrm{ppb}$ & $<10$ & $<10$ & $<10$ & $<10$ \\
\hline
\end{tabular}

Logo após, será mostrado nas figuras de 4 a 11 os resultados obtidos para a qualidade do vapor de baixa pressão da caldeira auxiliar da utilidade comparando com a especificação técnica internacional do EPRI.

\section{1 pH - Caldeira e Vapor de Baixa Pressão}

A figura 4 apresenta a monitoração química do valor de $\mathrm{pH}$ da caldeira com dosagem manual e após a implementação do controle químico de dosagem, o valor $\mathrm{d} \mathrm{pH}$ fica controlado. A dosagem química da caldeira é extremamente importante para deixar o meio alcalino da água minimizando a corrosão.

* Contribuição técnica ao $35^{\circ}$ Seminário de Balanços Energéticos Globais e Utilidades e $29^{\circ}$ Encontro de Produtores e Consumidores de Gases Industriais, 13 a 15 de agosto de 2014, São Paulo, SP, Brasil. 


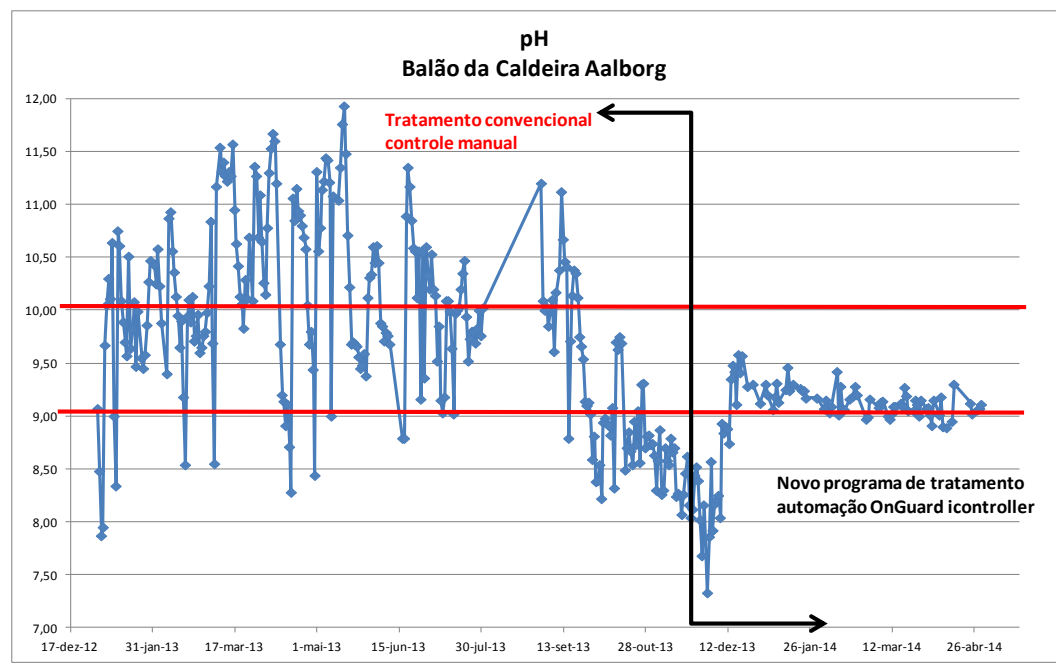

Figura 4. Monitoração química do $\mathrm{pH}$ da Caldeira

Com esta normalidade da dosagem química o vapor da caldeira encontra-se dentro da especificação técnica para a qualidade do vapor. Isto só pode ser observado a partir de 2014 quando se iniciou o monitoramento da qualidade do vapor de baixa pressão. Isto pode ser observado na figura 5.

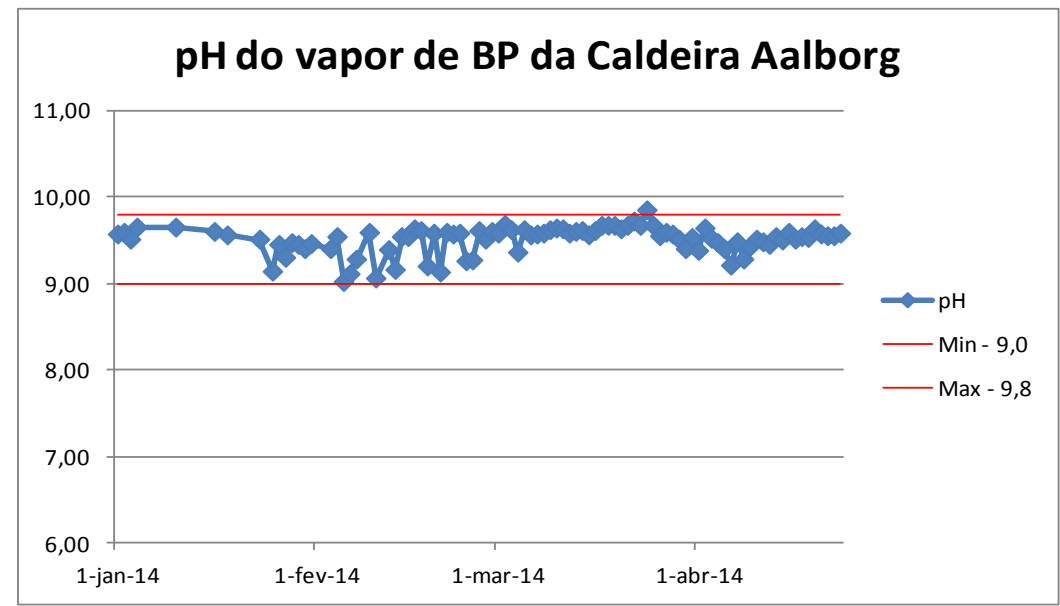

Figura 5. Monitoração química do $\mathrm{pH}$ do vapor (VBP)

\subsection{Condutividade - Caldeira e Vapor de Baixa Pressão}

O monitoramento da condutividade específica da caldeira é extremamente importante, pois o mesmo é que apresentará a presença de contaminante, que poderá ser da água ou da própria dosagem química. Durante a dosagem manual existia um descontrole que só pode ser ajustado após o programa do tratamento contínuo. Isto pode ser observado na figura 6.

* Contribuição técnica ao $35^{\circ}$ Seminário de Balanços Energéticos Globais e Utilidades e $29^{\circ}$ Encontro de Produtores e Consumidores de Gases Industriais, 13 a 15 de agosto de 2014, São Paulo, SP, Brasil. 


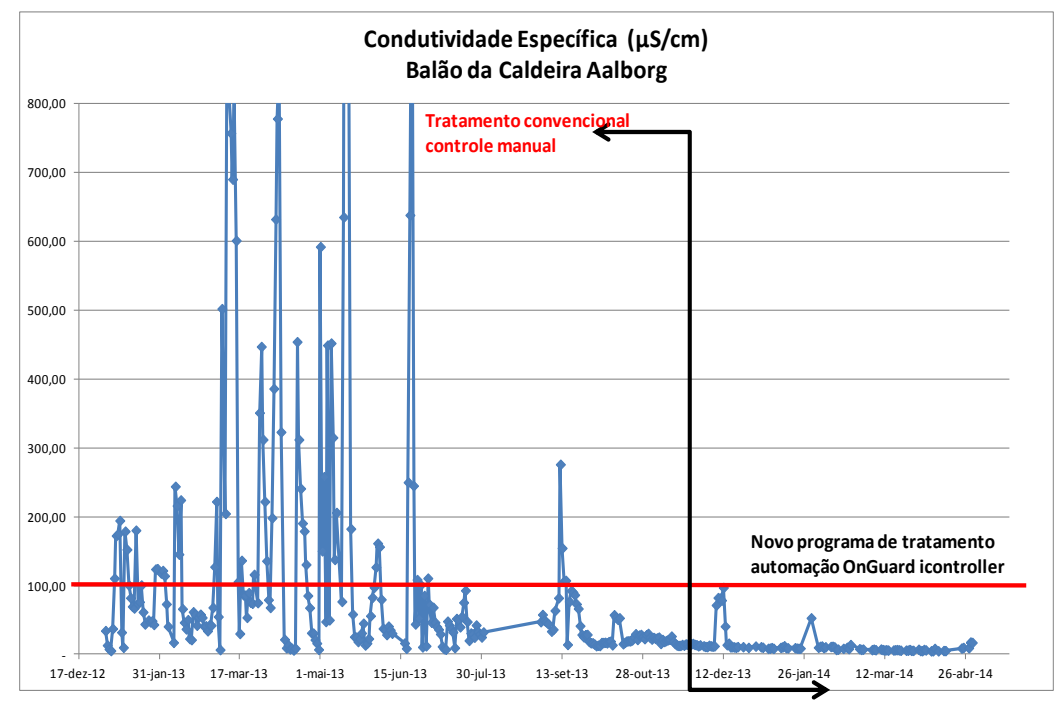

Figura 6. Monitoração química da condutividade da Caldeira

Todo descontrole de dosagem química acarreta ingresso de sais que afetaram a qualidade do vapor.

A figura 7 apresenta 0 equilíbrio da dosagem e 0 atendimento da especificação técnica do vapor.

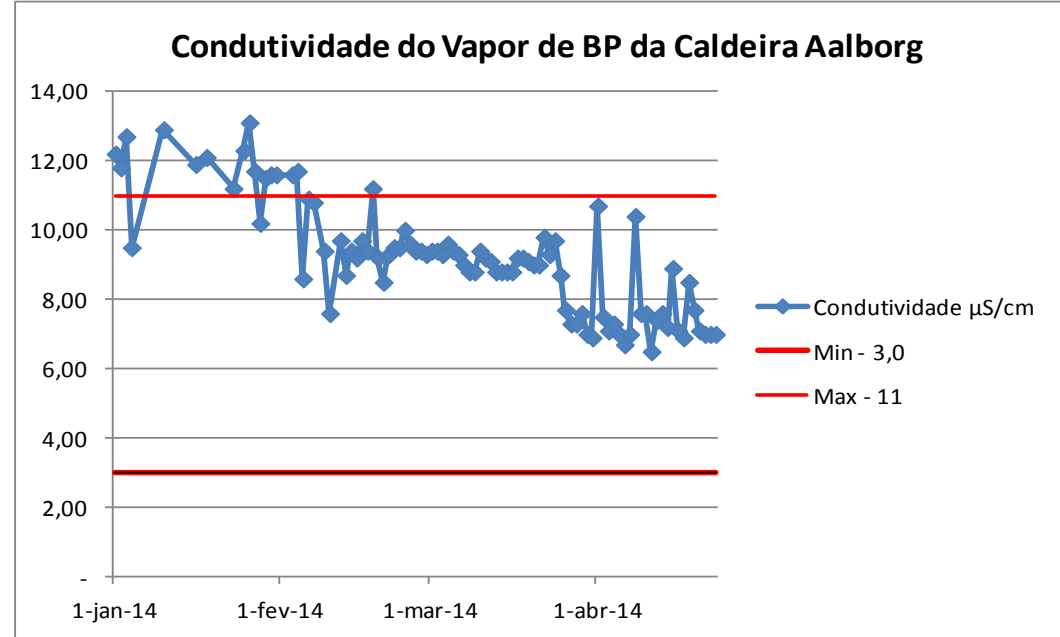

Figura 7. Monitoração química da condutividade do vapor (VBP)

Isto também pode ser melhor observado pela condutividade catiônica de te garante o vapor de qualidade.

\subsection{Sílica - Caldeira e Vapor de Baixa Pressão}

O parâmetro de sílica na caldeira é extremamente importante, pois todo excesso de sílica será volatilizado e se incrustará na paleta da turbina.

A monitoração contínua e o tratamento químico adequado favoreceram para minimizar estes acúmulos de sílica. A figura 8 apresenta claramente o descontrole quando se fazia a dosagem manual.

* Contribuição técnica ao $35^{\circ}$ Seminário de Balanços Energéticos Globais e Utilidades e $29^{\circ}$ Encontro de Produtores e Consumidores de Gases Industriais, 13 a 15 de agosto de 2014, São Paulo, SP, Brasil. 


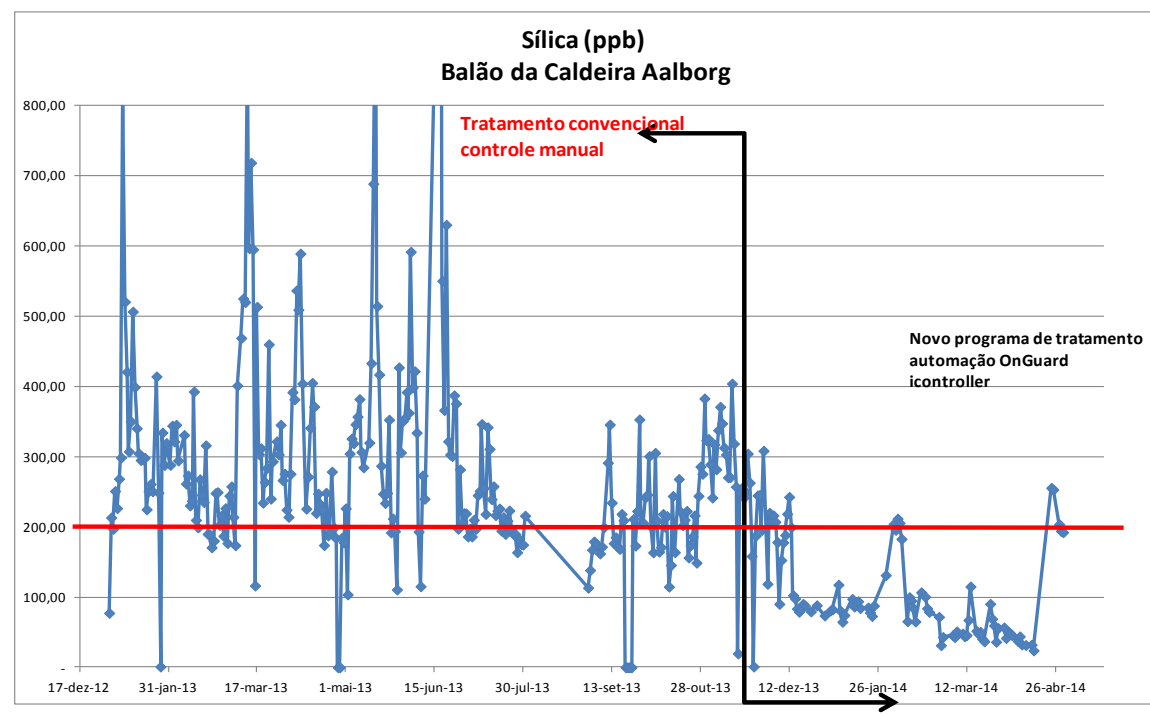

Figura 8. Monitoração química da sílica da caldeira

Observa-se claramente na figura 9 que o aumento de sílica na água da caldeira a mesma pode se concentrar até 20 vezes no vapor tornando um parâmetro preocupante para a paleta da turbina. O mesmo formará incrustação até ocasiona a quebra da paleta.

Após o controle e a monitoração química isto já esta contornado.

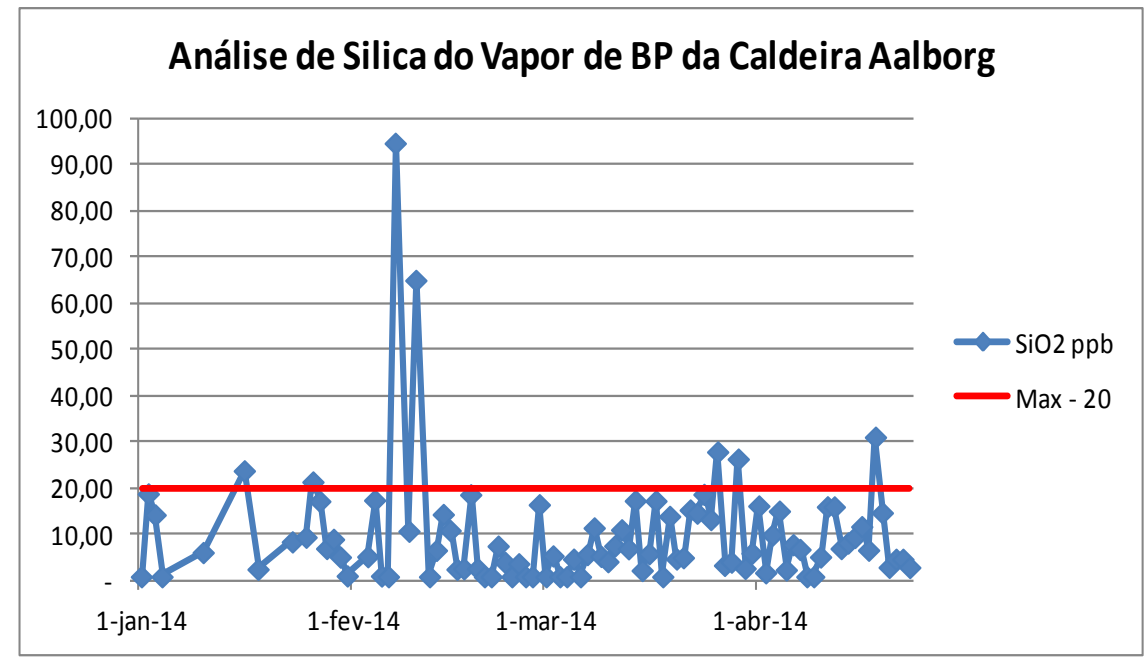

Figura 9. Monitoração química da sílica do vapor (VBP)

\subsection{Ferro - Caldeira e Vapor de Baixa Pressão}

O parâmetro de ferro na caldeira é extremamente importante ser monitorado pois o mesmo mostrará o acúmulo de sólidos depositados na caldeira podendo acarretar no aumento da corrosão e incrustação. A figura 10 apresenta a quantidade de ferro depositado e ou dissolvido na água da caldeira.

A monitoração contínua e o tratamento químico adequado favoreceram para minimizar estes depósitos, mas ainda é extremamente importante observar operacionalmente as necessidades das purgas da caldeira.

* Contribuição técnica ao $35^{\circ}$ Seminário de Balanços Energéticos Globais e Utilidades e $29^{\circ}$ Encontro de Produtores e Consumidores de Gases Industriais, 13 a 15 de agosto de 2014, São Paulo, SP, Brasil. 


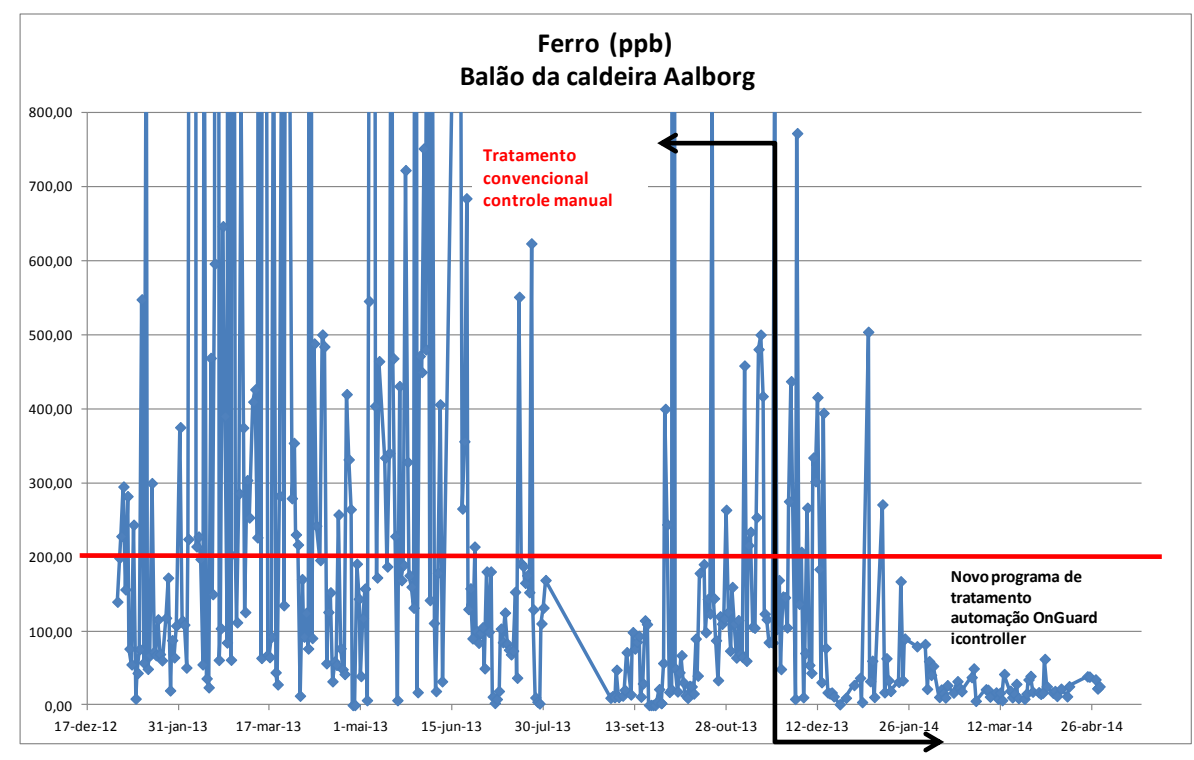

Figura 10. Monitoração química do ferro da caldeira

$\mathrm{Na}$ figura 11 observa-se que o vapor de baixa pressão ainda pode ser contaminado com ferro quando não se tem total domínio operacional da purga da caldeira. Isto já está sendo controlado pela modificação do procedimento operacional. Um não controle deste parâmetro o mesmo será arrastado junto com o vapor e irá para a turbina á vapor.

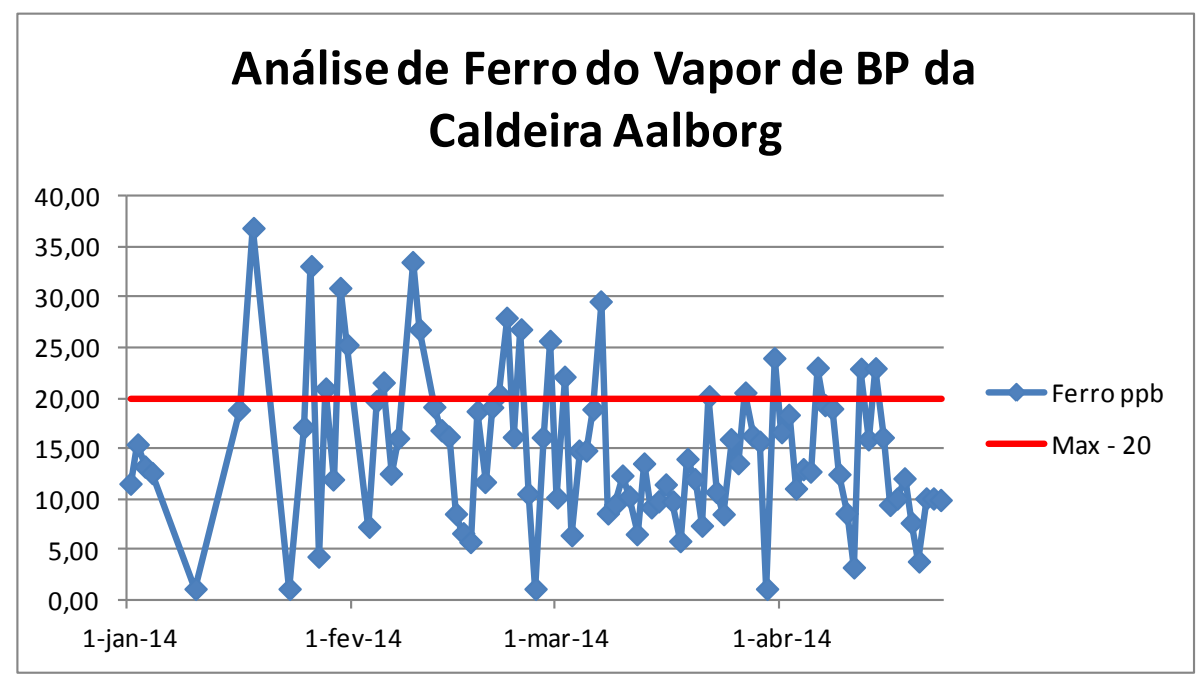

Figura 11. Monitoração química do ferro do vapor (VBP)

\section{CONCLUSÃO}

O desafio lançado para transformar o (VBP) da caldeira auxiliar da utilidade em vapor de mesma qualidade analítica do vapor produzido nas caldeiras recuperadoras de calor (HRSG) foi alcançado. Isto só foi possível após a implantação do tratamento e a monitoração química do controlador OnGuard iController. Contudo foi possível tornar um mecanismo dinâmico e econômico para a empresa viabilizando a utilização do vapor de baixa pressão para ser utilizado na termelétrica.

* Contribuição técnica ao $35^{\circ}$ Seminário de Balanços Energéticos Globais e Utilidades e $29^{\circ}$ Encontro de Produtores e Consumidores de Gases Industriais, 13 a 15 de agosto de 2014, São Paulo, SP, Brasil. 
A metodologia utilizada para esta adequação agora está sendo implantada pela área da Aciaria nas caldeiras de baixa pressão. Isto é extremamente importante para novos empreendimentos e melhoria contínua na geração e produção de vapor do complexo siderúrgico da TKCSA [5].

\section{Agradecimentos}

Este trabalho foi realizado junto ao grupo da Unidade Técnica, da Distribuição de Utilidades e da tratadora Ashland Water Technologies.

A Ashland Water Technologies pela tecnologia da monitoração e tratamento químico.

Agradecemos a Thyssenkrupp CSA pelo apoio nos dados para a implementação desde trabalho.

\section{REFERÊNCIAS}

1 Pinto MM. Curso Teórico de Monitoração Química do Ciclo água Vapor. 2011; p.71.

2 International Organization for Standardization. ISO 105234:2008: Water Quality Determination of $\mathrm{pH}$. Geneva; 2008.

3 ALSTOM. 1AHA056259: Water Chemistry Water/Steam Cycle Technical Specification. (Switzerland) Ltd., Brown Boveri Strasse 7, CH-5401 Baden.

4 EPRI - Electric Power Research Institute, Manufacturer's HRSG chemistry guidelines. EPRI Licensed Material 1998.

5 Techimical Guidance Document: Procedures for the Measurent of Carryover of Boiler Water into Steam, 2008. International Association for the Properties of Water and Steam.

* Contribuição técnica ao $35^{\circ}$ Seminário de Balanços Energéticos Globais e Utilidades e $29^{\circ}$ Encontro de Produtores e Consumidores de Gases Industriais, 13 a 15 de agosto de 2014, São Paulo, SP, Brasil. 